1 Fundação Oswaldo Cruz (Fiocruz), Escola Politécnica de Saúde Joaquim Venâncio (EPSJV) - Rio de Janeiro (RJ), Brasil. adelyne@fiocruz.br

2 Fundação Oswaldo Cruz (Fiocruz), Escola Nacional de Saúde Pública Sergio Arouca (Ensp) - Rio de Janeiro (RJ), Brasil. luciana@ensp.fiocruz.br

3 Fundação Oswaldo Cruz (Fiocruz), Escola Naciona de Saúde Pública Sergio Arouca (Ensp) - Rio de Janeiro (RJ), Brasil. cristiani@ensp.fiocruz.br

4 Instituto de Salud Carlos III, Escuela Nacional de Sanidad - Madrid, Espanha. jmfreire@isciii.es

\section{Descentralização e regionalização em saúde na Espanha: trajetórias, características e condicionantes}

\author{
Decentralization and regionalization in health in Spain: trajectories, \\ characteristics and conditions
}

Adelyne Maria Mendes Pereira', Luciana Dias de Lima², Cristiani Vieira Machado $\mathbf{3}$, José Manuel Freire $\mathbf{4}$

RESUMO O artigo aborda a descentralização e a regionalização do sistema de saúde espanhol no período de 1980 a 2012. Sob o enfoque do institucionalismo histórico, o estudo privilegiou a análise da trajetória, características e condicionantes desses processos, no contexto mais geral de redemocratização e reforma do Estado. Os resultados sugerem diferentes graus de poder entre os governos subnacionais e central nas dimensões política, administrativa e fiscal/financeira. Conclui-se que a redemocratização, as pressões regionalistas, a descentralização político-territorial e os antecedentes do sistema sanitário foram os principais fatores que influenciaram a configuração do sistema de saúde na Espanha.

PALAVRAS-CHAVE Descentralização; Regionalização; Sistemas de saúde.

ABSTRACT The article discusses the decentralization and regionalization of the Spanish health system from 1980 to 2012. Considering the historical institutionalism approach, the study analyzed the trajectory, characteristics and conditions of these processes, in broader the context of democratization and reform of the State. The results suggest different degrees of power between the central and subnational governments in the political, administrative and fiscal/financial dimension. It is concluded that the return to democracy, the regionalist pressures, the politicalterritorial decentralization and the antecedent of the health system were the main factors that influenced the configuration of the health system in Spain.

KEYWORDS Decentralization; Regional health planning; Health systems. 


\section{Introdução}

A partir da década de 1970, a descentralização destacou-se como uma das principais características dos processos de reforma dos Estados nacionais na Europa e América Latina. As reformas descentralizadoras assumiram sentidos e significados variados, desde a expressão de tendências democratizantes e participativas até a modernização gerencial da gestão pública com ênfase na eficiência e qualidade (FIORI, 1995; MELO, 1996; ARRETCHE, 1997; ABRUCIO, 2006).

As reformas de cunho descentralizador, implementadas por governos socialistas na Itália, França e Espanha, trouxeram impactos para a organização político-territorial desses Estados nos anos 1970 e 1980 (MELO, 1996). Salvo as diferenças, em geral, houve mudanças nas estruturas centralizadas de governo a partir da descentralização de poder para estruturas regionais. No caso da Espanha, a descentralização resultou na conformação de um novo nível de governo (as Comunidades Autônomas - CCAA) que, em um contexto de transição democrática, buscou responder à força e às pressões das identidades regionais (ARRETCHE, 1997; GARCIA; SOTELO, 1999).

Além das influências sobre a organização político-territorial dos Estados, as reformas descentralizadoras condicionaram processos de mudança nas políticas públicas e, entre elas, na saúde. Diversos países na Europa e América Latina implementaram reformas em seus sistemas sanitários, tendo a descentralização como uma diretriz importante, com início nos anos 1970 (ALMEIDA, 2008). Assim, a relação entre descentralização e regionalização no âmbito das reformas dos sistemas de saúde tem sido destacada nas experiências internacionais (SALTMAN; BANKAUSKAITE; VRANGBAK, 2007; MAINO ET AL., 2007) e na literatura nacional (LIMA ET AL., 2010; VIANA; LIMA, 2011), vinculadas à valorização do papel dos níveis regionais no planejamento e gestão desses sistemas.

Nos sistemas públicos - sejam universais ou baseados no emprego, constituídos em
Estados unitários ou federados -, salvo suas especificidades, descentralização e regionalização têm sido encontradas como diretrizes comuns para a organização do sistema de saúde. Sobretudo nos sistemas universais, a implementação articulada dessas diretrizes está relacionada com a garantia do acesso integral e equitativo a todos os cidadãos.

No tocante à regionalização da saúde, pode-se afirmar que, desde 1920 (DAWSON, 1964) até os anos 2000 (KUSCHNIR; CHORNY, 2010; VIANA; LIMA, 2011), tal conceito encontra-se remetido à organização do sistema de serviços em uma base territorial, considerando-se acesso, financiamento, infraestrutura e logística, a partir de um processo de planejamento que articula níveis regionais e níveis de atenção à saúde.

Contudo, para além da dimensão organizativa, o conceito de regionalização envolve questões políticas e de distribuição de poder no território. Assim, configura-se como um processo político dependente das relações intergovernamentais (VIANA ET AL., 2008) e entre Estado e sociedade civil (FLEURY; OUVERNEY, 2007).

Diante disso, e tendo em vista o marco institucionalista histórico, a análise empreendida está fundamentada em três argumentos principais:

1) Descentralização e regionalização configuram-se como processos políticos no quadro mais geral de reformas dos sistemas de saúde, que envolvem a articulação entre esferas de governo e assumem sentidos variados de acordo com o contexto institucional no qual são formuladas e implementadas. A descentralização se caracteriza pela transferência de poder e responsabilidades nas dimensões política, administrativa e fiscal/financeira. A regionalização está associada à organização do sistema de serviços de saúde em uma base territorial, por meio de um processo no qual níveis regionais são relacionados a níveis de atenção. Não obstante, a regionalização também pode estar referida à (re)organização do poder sobre o território. 
2) Existem visões e interesses diferentes entre os diversos atores envolvidos na arena de decisão da política sanitária, com repercussões sobre os processos de descentralização e regionalização dos sistemas de saúde. Como o conceito de descentralização é bastante amplo, o recorte do estudo irá privilegiar os atores governamentais.

3) Os processos de descentralização e regionalização dos sistemas de saúde, bem como a temporalidade e sequência entre as dimensões que os caracterizam, podem estar condicionados pelas mudanças no equilíbrio territorial do poder do Estado derivados dos processos de descentralização. Do mesmo modo, pode haver especificidades do setor saúde que influenciam tais processos.

Partindo desses argumentos, algumas questões foram construídas: Que fatores (históricos, políticos e institucionais) favoreceram os processos de descentralização e regionalização no sistema de saúde espanhol? Como tais fatores influenciaram a configuração recente desse sistema de saúde? Visando responder a tais questões, este estudo analisou os processos de descentralização e regionalização do sistema de saúde espanhol, no contexto de redemocratização e reforma desse Estado.

As justificativas do estudo repousam na relevância da compreensão dos condicionantes históricos, políticos e institucionais que se fazem presentes na trajetória da descentralização e da regionalização da política de saúde, bem como sua repercussão sobre a organização dos sistemas sanitários. Em que pesem as limitações inerentes ao desenvolvimento de estudos de caso (YIN, 2005), acredita-se que a análise do caso espanhol pode contribuir para ampliar olhares e horizontes sobre o caso brasileiro, favorecendo o entendimento do fenômeno e as discussões dessa natureza no campo da saúde coletiva no Brasil.

\section{Metodologia}

A partir da abordagem do institucionalismo histórico (THELEN; STEINMO, 1992; IMMERGUT, 1998; HALL; TAYLOR, 2003), sobretudo em suas contribuições para o estudo de políticas públicas, três eixos de análise foram definidos: 1) trajetória da descentralização e da regionalização da política de saúde; 2) institucionalidade da descentralização e da regionalização da saúde; e 3) condicionantes da descentralização e da regionalização da saúde.

A análise realizada articulou o estudo da descentralização e da regionalização da política de saúde com o contexto mais geral de descentralização do Estado. Para tanto, foram identificados os marcos institucionais e as principais características da descentralização do Estado e da saúde em cada uma das seguintes dimensões: política, administrativa e fiscal/financeira. Assim, foi possível estabelecer a sequência na qual se desenvolveram tais dimensões (no contexto do Estado e no âmbito da saúde) e compreender suas interfaces temporais (FALETTI, 2010).

Em cada uma das dimensões citadas, foram definidas variáveis, apresentadas no quadro 1. Visando facilitar a comparação entre tais dimensões em cada plano da investigação, tais variáveis foram valoradas segundo o grau de poder dos governos central e subnacionais. Na escala de valoração, foi atribuído (0) para ausência de poder, (1) para poder restrito e (2) para amplo poder, sendo o escore final de cada dimensão o resultado da média simples dos escores das variáveis. 
Quadro 1. Dimensões da descentralização no contexto do Estado e da política de saúde: definições e variáveis

\begin{tabular}{|c|c|c|c|c|}
\hline \multirow{2}{*}{$\begin{array}{c}\text { Dimensões da } \\
\text { Descentralização }\end{array}$} & \multicolumn{2}{|c|}{ Contexto do Estado } & \multicolumn{2}{|c|}{ Contexto da Política de Saúde } \\
\hline & Definições & Variáveis & Definições & Variáveis \\
\hline Política & $\begin{array}{l}\text { Compreende a } \\
\text { distribuição de poder } \\
\text { entre as esferas } \\
\text { subnacionais no que } \\
\text { tange à tomada de } \\
\text { decisão, formulação e } \\
\text { regulação de políticas } \\
\text { em seus territórios. } \\
\text { Inclui a eleição dos seus } \\
\text { governos. }\end{array}$ & $\begin{array}{l}\text { - Grau de poder dos governos } \\
\text { subnacionais para tomar decisões } \\
\text { acerca das políticas públicas } \\
\text { (competência na formulação e } \\
\text { regulação de políticas regionais); } \\
\text { - Competência para formular leis em } \\
\text { matérias regionais/locais; } \\
\text { - Eleição por voto direto; } \\
\text { - Competência para tratar questões } \\
\text { que envolvem o compartilhamento de } \\
\text { atribuições (representação regional dos } \\
\text { órgãos do judiciário). } \\
\text { Obs.: Valoração das variáveis: } \\
0=\text { sem poder } \\
1 \text { = poder restrito } \\
2 \text { = amplo poder }\end{array}$ & $\begin{array}{l}\text { Compreende a } \\
\text { transferência da } \\
\text { autoridade sanitária, } \\
\text { que envolve o poder } \\
\text { para a tomada de } \\
\text { decisão quanto } \\
\text { à formulação, } \\
\text { planejamento e } \\
\text { regulação da política de } \\
\text { saúde. }\end{array}$ & $\begin{array}{l}\text { - Grau de poder de formulação, } \\
\text { planejamento e regulação da } \\
\text { política sanitária pelos governos } \\
\text { subnacionais. } \\
\text { Obs.: Valoração das variáveis: } \\
0=\text { sem poder } \\
1=\text { poder restrito } \\
2 \text { = amplo poder }\end{array}$ \\
\hline Administrativa & $\begin{array}{l}\text { Compreende a } \\
\text { transferência de poder e } \\
\text { responsabilidades para } \\
\text { a gestão das políticas } \\
\text { públicas pelos governos } \\
\text { subnacionais. }\end{array}$ & $\begin{array}{l}\text { - Grau de poder dos governos } \\
\text { subnacionais para gerir os setores das } \\
\text { políticas públicas (competência para } \\
\text { executar a política e realizar a gestão do } \\
\text { trabalho e dos serviços). } \\
\text { Obs.: Valoração das variáveis: } \\
0 \text { = sem poder } \\
1=\text { poder restrito } \\
2 \text { = amplo poder }\end{array}$ & $\begin{array}{l}\text { Compreende a } \\
\text { transferência de poder } \\
\text { e responsabilidades } \\
\text { para a gestão } \\
\text { e prestação de } \\
\text { serviços de saúde } \\
\text { pelos governos } \\
\text { subnacionais. Inclui a } \\
\text { gestão das unidades, } \\
\text { equipamentos e } \\
\text { trabalhadores. }\end{array}$ & $\begin{array}{l}\text { - Grau de poder dos governos } \\
\text { subnacionais para exercer } \\
\text { a gestão das unidades, } \\
\text { equipamentos e força de } \\
\text { trabalho, bem como para realizar } \\
\text { a coordenação da rede de } \\
\text { serviços. } \\
\text { Obs.: Valoração das variáveis: } \\
0 \text { = sem poder } \\
1=\text { poder restrito } \\
2 \text { = amplo poder }\end{array}$ \\
\hline Fiscal/Financeira & $\begin{array}{l}\text { Compreende a } \\
\text { transferência de poder e } \\
\text { autoridade para instituir } \\
\text { e arrecadar tributos } \\
\text { da sua competência, } \\
\text { bem como para gestão } \\
\text { orçamentária pelos } \\
\text { governos subnacionais. }\end{array}$ & $\begin{array}{l}\text { - Grau de poder dos governos } \\
\text { subnacionais para instituir e arrecadar } \\
\text { tributos da sua competência, bem como } \\
\text { para manejar seu orçamento. } \\
\text { Obs.: Valoração das variáveis: } \\
0=\text { sem poder } \\
1=\text { poder restrito } \\
2 \text { = amplo poder }\end{array}$ & $\begin{array}{l}\text { Compreende a } \\
\text { transferência de poder } \\
\text { e autoridade para } \\
\text { manejar o orçamento e } \\
\text { decidir sobre gastos em } \\
\text { saúde pelos governos } \\
\text { subnacionais. }\end{array}$ & $\begin{array}{l}\text { - Grau de poder fiscal e de } \\
\text { gasto (gestão do orçamento) } \\
\text { dos governos subnacionais no } \\
\text { âmbito da saúde. } \\
\text { Obs.: Valoração das variáveis: } \\
0 \text { = sem poder } \\
1=\text { poder restrito } \\
2 \text { = amplo poder }\end{array}$ \\
\hline
\end{tabular}

Fonte: Elaboração própria.

O período de estudo compreendeu os anos de 1980 a 2012. Tal recorte temporal buscou abranger o período de reformas com ênfase na descentralização e regionalização, marcado inicialmente pela redemocratização e reforma do Estado (com início no final dos anos 1970) e que se estende até os dias atuais. A extensão do período de estudo foi importante para que se pudesse analisar a trajetória das diretrizes de descentralização e regionalização ao longo processo de implementação do sistema nacional de saúde.
A pesquisa envolveu levantamento e análise de material empírico acerca da trajetória da descentralização no contexto geral do Estado espanhol, bem como no contexto específico da saúde. Foram utilizadas fontes primárias (leis, atos normativos e documentos oficiais), secundárias (dados disponíveis publicamente em sites oficiais e publicações bibliográficas) e consultas a especialistas. Essa etapa foi desenvolvida durante estágio de doutorado no exterior, incluindo visitas técnicas a três comunidades autônomas (Andalucía, Cataluña 
e País Vasco), que facilitaram a compreensão das especificidades regionais que envolvem os processos em estudo. O projeto foi aprovado pelo Comitê de Ética em Pesquisa sob o Parecer n. ${ }^{\circ}$ 14/2012.

\section{Resultados e discussão}

\section{Descentralização do Estado espanhol: o caso das autonomias}

A Espanha é o segundo maior país da União Europeia em extensão territorial (505.987 $\mathrm{Km}^{2}$, depois da França) e o quinto maior em população (aproximadamente 46 milhões de habitantes, estando depois da Alemanha, França, Reino Unido e Itália) (INE, 2010). Após cerca de 40 anos de ditadura, marcada por fortes restrições às especificidades étnicas e linguísticas regionais, a Constituição de 1978 selou a redemocratização com um modelo de organização político-territorial que faz da Espanha um dos países mais descentralizados da Europa. Sendo chamada de Estado das Autonomias (REQUeJO, 2006; GARCíA; SOTELO, 1999), funciona de maneira semelhante a uma federação, apesar de ser, legalmente, um país unitário cujo regime político é uma Monarquia Parlamentarista.

Ao criar as CCAA, a Constituição (1978) definiu uma divisão político-administrativa em quatro níveis de governo: Governo central; 17 governos autônomos (CCAA); 50 governos provinciais e cerca de 8 mil governos locais. Além das 17 CCAA, a Constituição (1978) instituiu duas cidades autônomas (Ceuta e Mellila). O quadro 2 resume essas características.

Quadro 2. Divisão política e administrativa da Espanha: 17 Comunidades Autônomas (CCAA) e 50 províncias

\begin{tabular}{|c|c|c|c|}
\hline CCAA & População* & Capital & Número de províncias \\
\hline Andalucía & 8.371 .270 & Sevilla & 8 \\
\hline Cataluña & 7.519 .843 & Barcelona & 4 \\
\hline Madrid & 6.421 .874 & Madrid & 1 \\
\hline Comunidade Valenciana & 5.009 .931 & Valencia & 3 \\
\hline Galicia & 2.772 .928 & Santiago de Compostela & 4 \\
\hline Castilla-León & 2.540 .188 & Valladolid & 9 \\
\hline País Vasco & 2.185 .393 & $\star 1$ & 3 \\
\hline Ilhas Canarias & 2.082 .655 & $\star^{*} 2$ & 2 \\
\hline Castillla La Mancha & 2.106 .331 & Toledo & 5 \\
\hline Região de Murcia & 1.462 .128 & Murcia & 1 \\
\hline Aragón & 1.344 .509 & Zaragoza & 3 \\
\hline Extremadura & 1.104 .499 & Mérida & 2 \\
\hline Asturias & 1.075 .183 & Oviedo & 1 \\
\hline Ilhas Baleares (*3) & 1.100 .503 & Palma de Mallorca & 1 \\
\hline Navarra & 640.129 & Pamplona & 1 \\
\hline Cantabria & 592.542 & Santander & 1 \\
\hline La Rioja & 321.173 & Logroño & 1 \\
\hline Total & 46.815 .916 & Total & 50 \\
\hline
\end{tabular}

Fonte: Elaboração própria. Dados extraídos de La Moncloa (2012); INE (2013).

Notas: * População segundo Censo de 2011.

*1 País Vasco: Vitoria é a sede das instituições comuns da CCAA, mas a capital não está oficializada por lei.

*2 Ilhas Canárias: constituem um arquipélago formado por sete ilhas no Atlântico, quatro situadas na província de Santa Cruz de Tenerife e três na província Las Palmas de Gran Canaria. Em 1927, o Decreto Real de 21 de setembro definiu que, a cada legislatura, a sede do governo se alternaria entre as capitais das duas províncias.

*3 Ilhas Baleares: arquipélago formado por cinco ilhas (Menorca, Mallorca, Ibiza, Formentera e Cabrera) situadas no Mediterrâneo constituindo uma única província. 
Embora a Constituição (1978, art. 137) tenha definido que municípios, províncias e CCAA têm autonomia para a gestão de seus respectivos interesses, o que se nota é que a distribuição efetiva do poder se dá entre governo central e CCAA, restando às províncias e aos municípios um papel marginal e de responsabilidades restritas (GARCíA; SOTELO, 1999; AGRANOFF; RAMOS, 1998; ROCHA, 2013). O grau de poder e autonomia das províncias e municípios é variável entre as CCAA, pois depende do que foi estabelecido nos Estatutos de Autonomia de cada uma delas. Assim, nota-se, por exemplo, que os governos provinciais têm mais poder no País Vasco e menos, na Cataluña.

A disputa com relação à divisão de poderes e atribuições torna tenso o campo das relações intergovernamentais na Espanha. De maneira geral, a polarização entre governos central e regionais se manteve ao longo das décadas, com variações de intensidade. Tal disputa também assume os contornos da luta política e ideológica entre os partidos de esquerda e de direita que ocupam o executivo e legislativo nacional e regionais, manifestando-se nos fóruns de negociação compartilhada com prejuízos para seu funcionamento. $\mathrm{O}$ pêndulo dessa balança se mostrou mais favorável às CCAA, que ampliaram progressivamente suas competências ao longo dos anos 1980 e 1990, concretizando a descentralização política e administrativa, como se verá a seguir.

A análise do processo de descentralização do Estado espanhol revelou um sequenciamento, ainda que não linear, das dimensões política, administrativa e fiscal. Quanto à descentralização política, pode-se definir como período-chave aquele compreendido entre os anos 1979 e 1984, marcado institucionalmente pela definição do mapa político-territorial do Estado, seguido das eleições para as assembleias regionais e conformação dos governos autônomos. O desenho das CCAA evidencia diferenças importantes em extensão territorial, porte populacional, aspectos culturais e variações linguísticas, associadas à história de conformação desses territórios. Tais limites guardam relação com, ao menos, dois caminhos: a presença de uma identidade regional e características históricas que justifiquem a configuração de uma determinada CCAA; ou a vontade das províncias em se unirem ou não, enquanto uma CCAA. A análise do processo não sugere a relevância de critérios de eficiência administrativa.

A descentralização política criou condições para uma descentralização administrativa efetiva. O chefe do executivo regional tem ampla autonomia para tomar decisões quanto às políticas públicas, incluindo a formulação e regulação dessas políticas, tais como saúde e educação. Desde a constituição das CCAA, os governos regionais têm buscado legitimar e dar visibilidade a essa nova organização política por meio da coordenação e execução de políticas regionais.

Embora o processo de transferência de competências em algumas matérias tenha se estendido até os anos 2000, é possível destacar o período de 1980 a 1994 como um momento fundamental para a descentralização administrativa do Estado espanhol. Isto porque se caracterizou pelo intenso debate entre os diversos atores acerca da divisão de tarefas e responsabilidades entre os níveis de governo, bem como pela transferência da maior parte das competências na prestação de serviços às CCAA (JORDANA, 2006). Ao assumirem a responsabilidade pela gestão das políticas públicas, nota-se que as CCAA promoveram um aumento do gasto público, incluindo o aumento do gasto com pessoal e a ampliação do gasto social (CARRILLO, 1998).

A descentralização fiscal se estendeu e sofreu mudanças ao longo dos anos 1990 a 2000. Sobretudo nos anos 2000, quando se reduziram as tensões no que se refere à repartição de responsabilidades e competências, ganharam força as discussões acerca do financiamento das CCAA, bem como sobre a criação de símbolos e identidades territoriais. O modelo espanhol se caracteriza por uma centralização fiscal importante, na qual 
o governo central é responsável pela arrecadação praticamente total dos tributos e sua redistribuição, sendo exceções os casos do País Vasco e Navarra (que arrecadam todos os tributos e transferem ao nível central a parcela correspondente a serviços nacionais prestados em seus territórios).

As transferências financeiras realizadas pelo governo central se baseiam em critérios demográficos, geográficos e administrativos, bem como na renda per capita e no esforço fiscal de cada CCAA. Há que se reconhecer que o sistema fiscal espanhol logra um alto grau de cooperação e redistribuição, características viabilizadas pelo papel que ocupa o nível central nesse processo. Apesar da concentração central na arrecadação dos tributos, as CCAA possuem ampla autonomia para manejar seu orçamento e definir suas prioridades de gasto. As transferências se dividem em condicionadas e não condicionadas, e grande parte das condicionadas podem ser geridas livremente.

Há outra questão interessante que conforma uma espécie de paradoxo entre autonomia e responsabilidade fiscal no jogo de poder entre governos central e regionais (BAÑON I MARTINEZ; TAMAYO, 1998). Da parte das CCAA, ao mesmo tempo em que há a reivindicação pela autonomia na arrecadação de seus tributos visando à ampliação de seus recursos, há a rejeição dos custos políticos inerentes à responsabilidade pela pressão fiscal. Da parte do nível central, seria interessante repassar a competência de arrecadação para as CCAA, porque assim poderia responsabilizá-las por seus gastos; por outro lado, ao tomar essa medida, veria reduzido seu poder sobre a política econômica, o que não deseja. É notável um desajuste entre responsabilidade fiscal e de gasto que parece carecer de solução, sobretudo em tempos de crise econômica. Em geral, o modelo espanhol permitiu que as CCAA ampliassem seus gastos e suas dívidas e transferissem ao nível central o ônus político pela não execução de algum serviço social. Na ausência de um sistema de controle mútuo, tem-se como consequência um desequilíbrio financeiro para todo o Estado. Tal modelo também permitiu que o nível central se desresponsabilizasse pelas políticas sociais, transferindo ônus (e bônus) às CCAA.

Se por um lado o modelo de financiamento global favorece o poder e a autonomia das CCAA, permitindo que efetivem a descentralização política e administrativa; por outro, restringe a atuação do governo central, que na ausência de incentivos financeiros vê ainda mais reduzida sua capacidade de coordenar territorialmente as políticas públicas. Atualmente, a discussão em torno do financiamento autonômico se dá no âmbito do Ministério da Fazenda, tendo como instrumento o Conselho de Política Fiscal e Financeira, no qual não tem assento o Ministério da Saúde ou outro vinculado a políticas sociais. Tal Conselho possui potencial como espaço de gestão compartilhada, mas até o momento se configura como um fórum no qual se concretizam relações laterais entre cada CCAA e o Ministério da Fazenda, em um processo de negociação segmentada e assimétrica.

O quadro 3 apresenta algumas características da descentralização do Estado espanhol, em cada uma das dimensões estudadas. A partir das variáveis selecionadas (quadro 1), buscou-se valorar o grau de poder dos governos regionais no que diz respeito às dimensões política, administrativa e fiscal. A escala de valoração foi de (0) a (2), sendo: (0) para ausência de poder; (1) para poder restrito e (2) para amplo poder. 
Quadro 3. Descentralização política, administrativa e fiscal no contexto geral do Estado espanhol

\begin{tabular}{|c|c|c|c|}
\hline $\begin{array}{c}\text { Dimensões da } \\
\text { descentralização }\end{array}$ & Grau de poder dos governos regionais & Escore & Fontes \\
\hline \multirow[t]{2}{*}{ Dimensão política } & $\begin{array}{l}\text { - Amplo poder do executivo para tomar decisões (ampla competência } \\
\text { na formulação e regulação de políticas regionais) } \\
\text { - Amplo poder para formular leis em matérias regionais, embora } \\
\text { assimétrica entre as CCAA } \\
\text { - Poder parcial para eleger seus governantes (eleição por voto direto } \\
\text { em sistema de lista fechada para o legislativo; e indireta para o } \\
\text { executivo) } \\
\text { - Poder parcial do judiciário para tratar dos temas de compartilhamento } \\
\text { de atribuições (competência centralizada, contudo, há representação } \\
\text { regional dos órgãos do judiciário com competência para atuar sobre } \\
\text { temas regionais) }\end{array}$ & $\begin{array}{l}2 \\
1\end{array}$ & \multirow[t]{2}{*}{$\begin{array}{l}\text { Constituição, } \\
\text { Estatutos de Autonomia, } \\
\text { Documentos oficiais emitidos } \\
\text { por órgãos de cada poder, } \\
\text { Literatura secundária }\end{array}$} \\
\hline & Escore final & 1,5 & \\
\hline \multirow[t]{2}{*}{ Dimensão administrativa } & $\begin{array}{l}\text { - Amplo poder para realizar a gestão de recursos humanos no âmbito } \\
\text { das políticas públicas } \\
\text { - Amplo poder para realizar a gestão de equipamentos/serviços no } \\
\text { âmbito das políticas públicas }\end{array}$ & 2 & \multirow[t]{2}{*}{$\begin{array}{l}\text { Constituição, } \\
\text { Leis Orgânicas, } \\
\text { Literatura secundária }\end{array}$} \\
\hline & Escore final & 2 & \\
\hline Dimensão fiscal & $\begin{array}{l}\text { - Ausência de poder para instituir e arrecadar tributos da sua } \\
\text { competência* } \\
\text { - Amplo poder para manejar seu orçamento }\end{array}$ & 0 & $\begin{array}{l}\text { Constituição, } \\
\text { Lei 21/2001, } \\
\text { Lei 22/2009, } \\
\text { LOFCA (Ley Orgánica } \\
\text { de Financiación de las } \\
\text { Comunidades Autónomas), } \\
\text { Literatura secundária }\end{array}$ \\
\hline
\end{tabular}

Fonte: Elaboração própria.

Notas: *Exceção para as CCAA de País Vasco e Navarra.

Valoração das variáveis: 0 = sem poder; 1 = poder restrito; 2 = amplo poder. 0 escore final em cada dimensão é o resultado da soma dos escores de cada variável divido pelo número de variáveis. $\mathrm{O}$ escore máximo em cada dimensão é 2 .

A análise desse quadro sugere diferenças entre as dimensões, evidenciando maior poder dos governos regionais na dimensão administrativa, seguida pela política e, por último, a fiscal. A descentralização política, primeira dimensão a se desenvolver na trajetória espanhola, condiciona o grau de autonomia alcançado pelos governos regionais no que tange à dimensão administrativa - o mais alto entre o grupo de dimensões. A descentralização fiscal, última a se desenvolver, parece carecer de uma possível reformulação entre as competências e responsabilidades dos governos central e regionais.
Descentralização e regionalização da saúde na Espanha: análise histórica, institucional e política

\section{TRAJETÓRIA DA DESCENTRALIZAÇÃO E DA REGIONALIZAÇÃO DA POLÍTICA DE SAÚDE ESPANHOLA}

A trajetória da descentralização e da regionalização da saúde na Espanha está diretamente relacionada com o contexto político vivido pelo Estado no final dos anos 1970 e início dos 1980. A redemocratização do país trouxe consigo a reorganização territorial, na qual a descentralização política foi um marco fundamental, uma 
vez que respondia aos anseios nacionalistas (fortemente reprimidos ao longo da ditadura) e mantinha a unidade nacional. Pode-se afirmar que a descentralização política do Estado espanhol viabilizou a descentralização da política de saúde, que, por sua vez, colaborou para a visibilidade da nova organização político-territorial ante a população.

A Constituição Espanhola (1978) pode ser considerada o principal marco institucional dos processos de descentralização do Estado e da saúde. Por um lado, definiu a descentralização política, administrativa e fiscal mais geral do Estado, instituindo as CCAA; por outro, assegurou a proteção à saúde como direito fundamental dos cidadãos espanhóis, listou a 'saúde e higiene' entre as competências que poderiam ser transferidas às CCAA e definiu critérios para a regionalização.

Ao lado da Constituição (1978), a Lei Geral da Saúde (ESPAÑA, 1986) também é um marco da primeira grande reforma da saúde espanhola, pois lançou os pilares para a estruturação do Sistema Nacional de Saúde (SNS), a progressão da universalização e o financiamento por impostos. Tal fato, somado ao Decreto de Universalização da Atenção Sanitária (1989), promoveu uma 'universalização de fato' (quase de $100 \%$ ao início dos anos 1990), ainda que não 'de direito', como argumenta Freire (2005).

A análise da dimensão política põe em evidência o período de 1979 a 1994, sendo possível destacar ao menos dois momentos: o primeiro (1979 a 1985), marcado pela transferência das competências em saúde pública e autoridade sanitária do nível central para as CCAA, após aprovação dos seus Estatutos de Autonomia; e o segundo (1981 a 1994), no qual se deu a organização dos Serviços de Saúde Regionais em sete CCAA. Cabe destacar que a descentralização política se caracteriza pela transferência do poder de decisão quanto à formulação, planejamento e regulação da política de saúde, bem como dos serviços, do nível central para os níveis regionais (CCAA). Tal processo não foi acompanhado pelo desenvolvimento de condições ideais de coordenação geral do SNS pelo governo central, de modo que o balanço entre os poderes (central e regional) indica uma limitação da atuação central para induzir políticas nacionais ou conduzir o fórum de negociação interterritorial.

A dimensão administrativa se mistura com a política em função do processo assimétrico de constituição das CCAA espanholas. Tem início com a transferência da gestão de centros e redes específicas (quantitativamente pouco significativos) em 1980 e se encerra com a finalização da descentralização dos serviços vinculados ao Seguro Social (por meio do Instituto Nacional de la Salud - Insalud) em 2002. Caracteriza-se pela transferência de amplo poder às CCAA para realizar a gestão dos equipamentos, trabalhadores e rede de serviços, em um processo que destitui o nível central de qualquer competência nesse sentido (salvo nas cidades autônomas de Ceuta e Melilla, embora haja uma discussão que essa atribuição deveria ser repassada à CCAA de Andalucía em função da proximidade territorial). Cada CCAA organizou (e reorganizou ao longo dos anos) o serviço de saúde a sua maneira, havendo diferentes formas de gestão implementadas (algumas pautadas pela Administração Direta, outras por Organizações Públicas de Direito Privado e outras por convênios com o setor privado).

A dimensão fiscal/financeira da descentralização sanitária se confunde temporalmente com a segunda reforma do SNS, tendo como marco o ano de 2002. Em 1995, quando a competência sanitária já havia sido transferida para sete CCAA, o gasto da Seguridade Social em Saúde correspondia a cerca de $24 \%$ do gasto público em saúde; a partir de 2002, quando tal transferência se concluiu, esse percentual se manteve em cerca de 7\% (WHO, 2014). Em 2002, ocorreram as mudanças nas regras do financiamento da saúde, que passou de um 'financiamento finalista' para compor o orçamento geral das CCAA. Esse fato foi decisivo para a conclusão do processo de descentralização administrativa. Além disso, foi promulgada a Lei de Coesão e Qualidade do SNS (2003), que trouxe, entre seus dispositivos mais 
importantes, o Fundo de Coesão, com o objetivo de financiar os serviços de alto custo prestados a cidadãos fora das CCAA de domicílio.

A terceira reforma do SNS se deu em 2012. Foi marcada pela publicação do Real Decreto 16/2012, que visou promover a redução da 'universalização' (com a exclusão da cobertura sanitária aos imigrantes ilegais e a jovens de mais de 25 anos que nunca contribuíram para a Seguridade Social). Tal Decreto buscou destituir o SNS espanhol do marco beveridgiano, em um regresso a um modelo no qual o acesso é dado pela vinculação à Previdência Social. Foi gestado em um contexto político-institucional de crise econômica e de um governo nacional de direita (Partido Popular - PP), tendo como principal objetivo a redução dos gastos em saúde (inclusive pela incorporação de copagamentos mais extensivos na área de medicamentos). Tal momento veio acompanhado por processos (ou tentativas) de privatização em diferentes CCAA, com destaque para os casos de Madrid e da Comunidade Valenciana. Algumas CCAA reagiram a essa proposta, entrando com ações na justiça para derrubá-la.
Em um balanço da descentralização da saúde na Espanha, pode-se afirmar que as CCAA possuem amplo poder para formular, planejar e regular a política sanitária em seus territórios, bem como para gerir a rede de serviços, equipamentos e trabalhadores. Ainda que não tenham amplo poder fiscal, as CCAA possuem amplo poder para gerir os recursos da saúde. Além disso, o nível central possui baixa capacidade de induzir ou coordenar a política de saúde, pois as características da descentralização política, administrativa e fiscal mais geral do Estado atuam como condicionantes e contingenciam sua atuação.

O quadro 4 busca sintetizar a discussão realizada, apresentando o grau de poder dos governos central e regionais em cada uma das dimensões da descentralização da saúde. As variáveis selecionadas foram valoradas de (0) a (2), sendo: (0) para ausência de poder, (1) para poder restrito e (2) para amplo poder; sendo o escore final de cada dimensão o resultado da média simples dos escores das variáveis. A análise sugere que a descentralização sanitária significou a ampliação do poder regional em todas as dimensões estudadas. O grau de poder do governo central

Quadro 4. Descentralização política, administrativa e fiscal no contexto do sistema de saúde espanhol

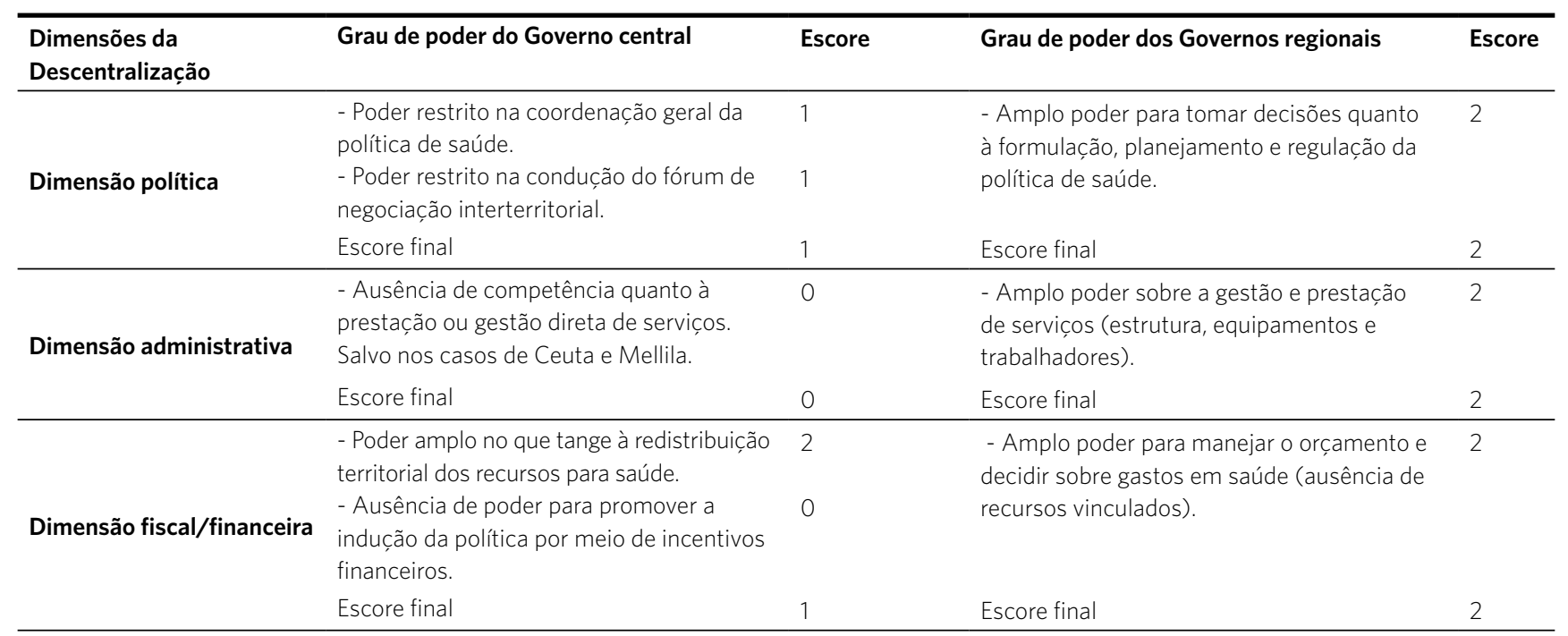

Fonte: Elaboração própria.

Notas: Valoração das variáveis: 0 = sem poder; 1 = poder restrito; 2 = amplo poder. 0 escore final em cada dimensão é o resultado da soma dos escores de cada variável divido pelo número de variáveis. 0 escore máximo em cada dimensão é 2. 
parece reduzido nesse contexto, em função da baixa capacidade de exercer a coordenação e/ou indução da política de saúde.

Quanto à regionalização da saúde, há evidências de que ela foi influenciada pelo processo de expansão da cobertura populacional e territorial na vigência do modelo de seguro social, bem como pela reforma da atenção primária, que se deu em 1984, antes da maior parte da descentralização sanitária. Tais aspectos contribuíram para que o sistema espanhol recebesse um legado de menores desigualdades em termos da distribuição territorial dos serviços de saúde.

\section{CARACTERÍSTICAS FORMAIS DA DESCENTRALIZAC̣ÃO E DA REGIONALIZAC̣ÃO DA SAÚDE}

$\mathrm{O}$ arcabouço legal no qual se ancoram os princípios e diretrizes organizativos do SNS espanhol está conformado pela Constituição Espanhola (1978), Lei Geral da Saúde (ESPAÑA, 1986) e Lei de Coesão e Qualidade do Sistema Nacional de Saúde (2003). A ideia/sentido formal da descentralização está relacionada com a devolução da competência sanitária às CCAA, ou seja, à transferência de poder decisório nas dimensões política, administrativa e financeira. Trata-se de uma característica intrínseca e condicionada pelo processo mais geral de descentralização do Estado espanhol, que se efetivou com a aprovação dos Estatutos de Autonomia das CCAA.

Quanto à regionalização, a ideia/sentido formal diz respeito à organização territorial dos serviços de saúde, a partir do desenho de áreas e zonas. As áreas de saúde foram definidas legalmente como estruturas fundamentais do sistema sanitário, estabelecidas para garantir a integralidade da atenção (ESPAÑA, 1986). Foi proposto que elas abrangessem entre 200 e 250 mil habitantes, salvo as exceções que se fizessem necessárias, e que desenvolvessem atividades de atenção primária e especializada. As zonas de saúde foram instituídas como o marco territorial da atenção primária, onde se desenvolveriam atividades sanitárias vinculadas aos centros de saúde.
Sobre os objetivos ou desenho formal da descentralização e regionalização da saúde, é possível afirmar que envolvem a integralidade da atenção, a coordenação assistencial, a gestão descentralizada e participativa, bem como a ideia de que os serviços estejam mais próximos dos usuários. Entre as instituições presentes no processo de formulação e implementação da política sanitária, estão os governos central e autonômicos, partidos políticos (destaque para o Partido Socialista Espanhol - PSOE e Partido Popular - PP) e o Tribunal Constitucional, responsável por mediar conflitos entre os níveis de governo.

Como resultado do processo mais geral de descentralização do Estado Espanhol, e do processo específico de descentralização e regionalização da saúde, as CCAA se constituíram como nível intermediário de governo dotado de amplo poder e responsabilidade sobre a gestão e prestação dos serviços. Do ponto de vista organizativo, o Serviço Sanitário Regional, em cada CCAA, reuniu todos os centros de saúde, serviços e estabelecimentos da própria CCAA, das províncias e municipalidades. Esse pode ser um aspecto diferencial do caso espanhol, uma vez que a constituição do Serviço Sanitário Regional representou a concentração e integração da gestão dos serviços no nível político e administrativo das CCAA, desprovendo províncias e municipalidades dessa responsabilidade, nos termos da Lei Geral da Saúde (ESPAÑA, 1986).

O governo central é responsável por garantir níveis de equidade entre os Serviços Regionais de Saúde, cabendo a ele definir a Carteira de Serviços Básicos comuns a todas as CCAA. Essa carteira, que se refere ao conjunto de técnicas, tecnologias ou procedimentos mediante os quais se torna efetiva à assistência à saúde, é atualizada periodicamente, sendo a última publicada pelo Real Decreto 1.030/2006. Sendo assim, a atual carteira inclui serviços de saúde pública; saúde mental; atenção primária; atenção especializada; urgência; atenção à dependência química; cuidados paliativos; atenção odontológica (extrações e urgências); assistência 
farmacêutica; órtese e prótese; nutrição (especial, enteral); transporte sanitário; informação e documentação sanitária.

Foram previstos, legalmente, órgãos participativos nas áreas de saúde tanto para interação com a sociedade civil (Conselhos de Participação) quanto para integração entre os gestores (Conselhos de Direção e Gestão). Segundo Aguilar (2001), os Conselhos de Participação funcionam razoavelmente (com regularidade moderada e assimétrica entre as CCAA), mas os Conselhos de Direção e Gestão não funcionam, estando o poder de decisão concentrado na CCAA. O Conselho Interterritorial tem dificuldades para se efetivar como fórum de negociação e gestão compartilhada, dado que é frequentemente palco de disputas políticas e da expressão da lógica de maximização das autonomias (FREIRE, 2008).

\section{CONDICIONANTES DA DESCENTRALIZAC̣ÃO E DA REGIONALIZAC̣ÃO DA SAÚDE}

A democracia espanhola está marcada pela sucessão de partidos de esquerda e de direita no executivo nacional, comumente relacionada com momentos de crise institucional, política ou financeira. As posturas político-ideológicas desses partidos trazem consequências para a organização e funcionamento do sistema de saúde espanhol, atuando como condicionantes da descentralização e da regionalização. Nuances variadas podem ser notadas entre as CCAA, uma vez que elas possuem ampla autonomia na formulação, gestão, prestação e regulação da política de saúde, bem como grande autonomia para decidir sobre seu orçamento e os gastos em saúde. Esse fato faz com que a presença de governos de direita ou de esquerda nos governos regionais seja também um condicionante para o sistema de saúde.

Cabe ao nível central exercer a coordenação nacional e atuar no sentido de reduzir essas diferenças, papel que tem dificuldade de executar diante das características e condicionantes do processo de descentralização do Estado e da saúde. Ainda cabe ao governo central responsabilizar-se pela saúde exterior e pela política de medicamentos, enquanto as províncias e municípios têm um papel marginal nos rumos do sistema de saúde. Identificam-se as seguintes estratégias de atuação das instituições e dos atores: o governo central busca manter algum poder no seu nível, os governos regionais buscam ampliar suas autonomias e o Tribunal Constitucional atua como moderador.

Em suma, entre os fatores político-institucionais que atuaram/atuam como condicionantes da descentralização e da regionalização da saúde na Espanha, situam-se o contexto de redemocratização e o ideal de manutenção da unidade, decisivos para a descentralização política do Estado; os regionalismos e tendências separatistas, que atuam como maximizadores das autonomias regionais; a descentralização do Estado espanhol e constituição das CCAA, fato inicial para a descentralização no âmbito da saúde; o ingresso da Espanha na União Europeia e o aporte financeiro que trouxe para as CCAA investirem na área social; a expansão do sistema de proteção social antes da criação do SNS, que condicionou a organização territorial interna às CCAA; e, por último, o modelo de financiamento da saúde, antes e depois de 2002.

Os fatores econômicos não são menos importantes, podendo-se perceber as influências das crises dos anos 1980 (com início no final da década de 1970) e de 2009 sobre a gestão e o financiamento do SNS. A diferença é que, na crise de 1980, estando o governo socialista no executivo nacional, as medidas estiveram centradas na redução de investimentos, com repercussão sobre a fila de espera. No âmbito da crise de 2009, e sobretudo a partir de 2012 com um executivo nacional de direita, as medidas têm sido de abertura do sistema público ao capital privado por meio de medidas privatizadoras e de restrição do acesso (imposição de limites ao caráter universal do sistema e instituição de copagamentos).

A partir da matriz de análise proposta para este estudo, o quadro 5 apresenta a trajetória, 
Quadro 5. Análise histórica, institucional e política da descentralização e da regionalização da saúde na Espanha

\begin{tabular}{|c|c|}
\hline Eixos & scentralização e Regionalização da Política de Saúde Espanhola \\
\hline $\begin{array}{l}\text { Trajetória da } \\
\text { descentralização } \\
\text { e da } \\
\text { regionalização da } \\
\text { política de saúde }\end{array}$ & $\begin{array}{l}\text { - Marcos institucionais: Constituição Espanhola (1978); Lei Geral da Saúde (ESPAÑA, 1986); Lei de Coesão e Qualidade (2003). } \\
\text { - Características: Processo de descentralização sanitário paulatino, assimétrico entre as regiões, na sequência: política, administrativa } \\
\text { e fiscal. Resulta na conformação de } 17 \text { Serviços Regionais de Saúde (um em cada Comunidade Autônoma - CCAA). As CCAA } \\
\text { possuem amplo poder para formular, planejar e regular a política de saúde em seus territórios, bem como para gerir a rede de serviços, } \\
\text { equipamentos e trabalhadores. Ainda que não tenham amplo poder fiscal, as CCAA possuem amplo poder para gerir os recursos da } \\
\text { saúde (os recursos não são condicionados). O nível central possui baixo poder e capacidade para induzir ou coordenar a política de } \\
\text { saúde, pois as características da descentralização política, administrativa e fiscal mais geral do Estado atuam como condicionantes e } \\
\text { contingenciam sua atuação. } \\
\text { - Ruptura de um modelo centralizado (Insalud) para um descentralizado (SNS). A redemocratização, as pressões regionalistas e a } \\
\text { descentralização político-territorial atuam como questões contingenciais do processo de descentralização da saúde. } \\
\text { - Traços de continuidade na organização territorial dos serviços de saúde (regionalizaccão). A extensão do modelo de proteção social } \\
\text { logrou uma ampla cobertura sanitária (populacional e territorial) antes da implementação do SNS, condicionando a sequência da } \\
\text { descentralização e regionalização da saúde. }\end{array}$ \\
\hline $\begin{array}{l}\text { Institucionalidade } \\
\text { da } \\
\text { descentralização } \\
\text { e da } \\
\text { regionalização } \\
\text { da saúde }\end{array}$ & 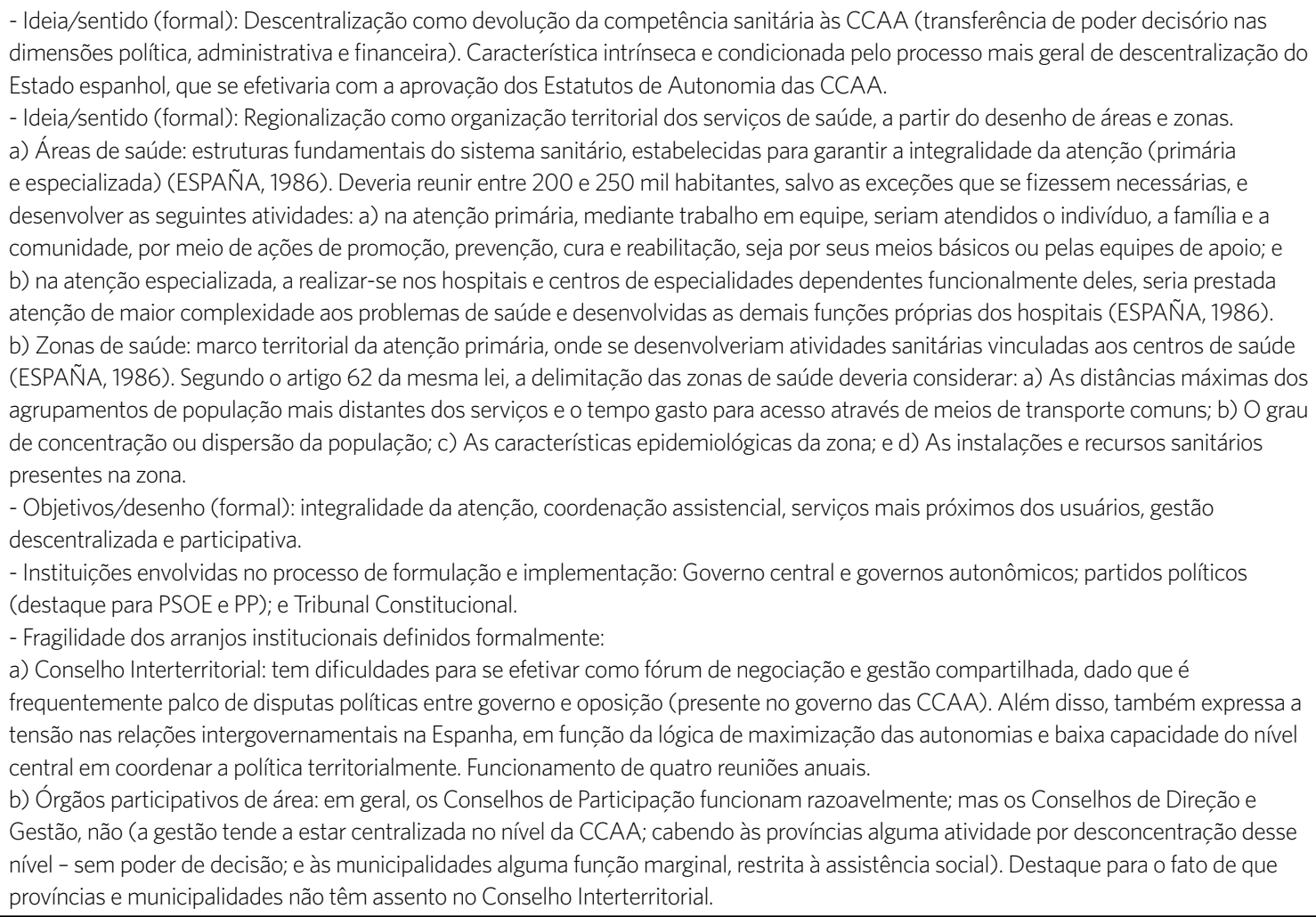 \\
\hline $\begin{array}{l}\text { Condicionantes } \\
\text { da } \\
\text { descentralizaçã } \\
\text { e da } \\
\text { regionalização } \\
\text { da saúde }\end{array}$ & $\begin{array}{l}\text { - Períodos de governo de centro: 1976-1981 (UCD - Adolfo Suarez) } \\
\text { - Períodos de governo de esquerda: 1982-96 (PSOE - Gonzalez); 2004-2011 (PSOE - Zapatero) } \\
\text { - Períodos de governo de direita: 1996-2003 (PP - Aznar); 2012-presente (PP - Rajoy). } \\
\text { - Papel das instituições e dos atores: os governos regionais (CCAA) possuem amplas competências na formulação, gestão, } \\
\text { prestação e regulação da política de saúde, bem como amplo poder para decidir sobre seu orçamento e os gastos em saúde. } \\
\text { Ao nível central cabe exercer a coordenação nacional (papel difícil de executar diante das características e condicionantes } \\
\text { do processo de descentralização do Estado e da saúde), bem como responsabilizar-se pela saúde exterior e política de } \\
\text { medicamentos. Províncias e municípios têm um papel restrito. } \\
\text { - Estratégias de atuação das instituições e dos atores: governo central busca manter algum poder no nível central; governos } \\
\text { regionais buscam ampliar seu poder e autonomia; e Tribunal Constitucional atua como moderador. } \\
\text { - Fatores político-institucionais: redemocratização; regionalismos e tendências separatistas; descentralização do Estado } \\
\text { espanhol (constituição das CCAA); ingresso na União Europeia, em 1986; expansão do sistema de proteção social antes da } \\
\text { criação do SNS; e modelo de financiamento da saúde, antes e depois de 2002. } \\
\text { - Fatores econômicos: crise de 1980, com repercussões para o financiamento da saúde; crise de 2009, com impactos sobre a } \\
\text { universalidade do sistema e tendência a privatizações. }\end{array}$ \\
\hline
\end{tabular}

Fonte: Elaboração própria. 
a institucionalidade (características formais) e os condicionantes da descentralização e regionalização da saúde na Espanha.

\section{Considerações finais}

Esta seção tem como objetivo apresentar algumas considerações sobre os processos de descentralização e regionalização da política de saúde espanhola. Para tanto, cabe retomar as questões iniciais: Que fatores históricos, políticos e institucionais favoreceram tais processos? Como tais fatores influenciam a configuração recente do sistema de saúde? Os argumentos que respondem a tais questões foram apresentados ao longo do artigo e servirão como base para reflexões sobre algumas tendências e possibilidades.

$\mathrm{Na}$ Espanha, a reforma descentralizante do Estado e as características que assumiu em termos da redistribuição do poder político-territorial constituem-se como variáveis estruturantes da trajetória da descentralização da saúde. A descentralização sanitária está marcada temporalmente pela constituição das CCAA, como novo nível de governo dotado de significativa autonomia e considerável poder de decisão sobre a formulação, regulação e execução de políticas públicas. Tal configuração repercutiu diretamente sobre a definição da CCAA como a esfera de governo que detém o poder de autoridade sanitária e concentra a maior responsabilidade pela coordenação da política e do sistema de saúde no seu território.

A análise da trajetória da descentralização e da regionalização da saúde mostra que as CCAA possuem amplo poder político, administrativo e fiscal/financeiro na política sanitária, características que guardam relação com o amplo poder de decisão que lhes foi transferido no contexto da descentralização do Estado. Ressaltam-se como condicionantes desses processos: a expansão da infraestrutura pública de serviços e da cobertura populacional antes da instituição do
SNS; a atuação do PSOE nos primeiro anos da reforma sanitária e o ingresso da Espanha na União Europeia; e a estrutura do financiamento do setor, na qual predomina o gasto público. A associação desses fatores favoreceu a descentralização e a regionalização da saúde no caso espanhol, com influências sobre o desenho recente do sistema sanitário.

Contudo, percebe-se que o arranjo intergovernamental de poder na Espanha não favoreceu o estabelecimento de relações articuladas entre as esferas de governo, com prejuízos para o papel do governo central em sua função de coordenar nacionalmente a política e o Conselho Interterritorial. Tal fato segue como um desafio do SNS, tendo em vista as preocupações com a unidade do sistema e a equidade entre as CCAA. O caso espanhol é um exemplo de que a maximização da autonomia dos governos subnacionais repercute sobre as relações intergovernamentais, em uma lógica onde maior autonomia subnacional corresponde a menor coordenação e cooperação intergovernamental.

$\mathrm{Na}$ atualidade, o contexto democrático espanhol está marcado por manifestações sociais que expressam o descontentamento de parcela da população com a condução dos governantes sobre diversos temas. Destacase o movimento que congregou profissionais da saúde, usuários do sistema sanitário e partidos políticos de esquerda a fim de combater a proposta de privatização de hospitais públicos de Madri. Trata-se de um momento histórico relevante, no qual a articulação e organização da sociedade têm assumido especial importância.

A análise realizada também permitiu identificar algumas tendências na gestão do sistema de saúde espanhol. Por um lado, percebem-se movimentos de privatização, que assumem variadas formas e põem em risco princípios do sistema. Por outro, é possível verificar uma tendência à gestão do território, ou seja, à unificação da gestão da rede de atenção primária e da especializada/ 
hospitalar, presentes em uma dada região de saúde, em uma direção única. O objetivo desta direção única é promover a integração entre os níveis assistenciais com vistas à melhoria da eficiência na gestão e prestação de serviços. Tal experiência está em curso em algumas CCAA e deverá ser alvo de avaliações posteriores. Pode-se afirmar que as possibilidades de avanço do sistema de saúde espanhol estão relacionadas com os rumos que tomará em cada um desses dois aspectos.

O estudo do caso espanhol sugere que os processos de descentralização e regionalização da saúde foram condicionados por uma série de fatores, entre eles: a divisão político-territoral e as características da descentralização do Estado; os processos de democratização e reforma do Estado; as conjunturas econômicas e políticas das décadas analisadas; os antecedentes do sistema de saúde (infraestrutura pública e cobertura populacional prévias à reforma sanitária); as características da trajetória da descentralização e da regionalização da saúde; as condições e o modelo de financiamento da política de saúde; o papel e as estratégias das instituições e atores. Tais fatores podem favorecer ou desfavorecer a descentralização e regionalização da saúde, apontando que o modo como se inter-relacionam no tempo importa para o resultado da sua atuação.

A influência desse conjunto de fatores sobre a formulação e implementação da descentralização e da regionalização da política de saúde, na Espanha, repercutiu sobre a configuração atual do sistema de saúde, determinando aspectos relativos à organização territorial dos serviços; ao balanço de poder entre as esferas governamentais na gestão do sistema; ao ator que detém maior responsabilidade na coordenação da política; e à repartição de responsabilidades sobre o financiamento do setor.

Por fim, cabe ressaltar as limitações desta pesquisa. Em função do seu foco, ela dedicou-se a observar a descentralização e a regionalização em saúde a partir do Estado, restringindo-se à análise dos atores e instituições governamentais. Todavia, a compreensão da política de saúde possui outras facetas relevantes, que dependem de investigações acerca do mercado e da sociedade. Como agenda de pesquisa, ressalta-se a importância de que outros estudos voltem sua atenção para tais questões, assim como para debates referentes à organização da rede de saúde e sua articulação a partir da atenção primária, à relação público-privada no âmbito das regiões de saúde e à gestão local/ regional e o estímulo à participação social.

\section{Referências}

ABRUCIO, F. L. Para além da descentralização: os desafios da coordenação federativa no Brasil. In: FLEURY, S. (Org.). Democracia, descentralização e desenvolvimento: Brasil e Espanha. Rio de Janeiro: Editora FGV, 2006. p. 77-125.

AGRANOFF, R.; RAMOS, J. A. La evolucíon hacia una democracia federal en España: un examen del sistema de relaciones intergubernamentales. In: AGRANOFF,

\author{
R.; BAÑON i MARTINEZ, R. (Org.). El Estado de las \\ Autonomías: hacia um nuevo federalismo? Bilbao: Instituto \\ Vasco de Administración Pública, 1998. p. 55-103.
}

AGUILAR, J. M. La participación comunitaria en salud: mito o realidad? Evaluación de experiencias en atención primaria. Madrid: Díaz de Santos, 2001. 
ALMEIDA, C. M. Reformas de sistemas de saúde: tendências internacionais, modelos e resultados. In.: GIOVANELLA, L. et al. Políticas e sistema de saúde no Brasil. Rio de Janeiro: Editora Fiocruz, 2008. p. 871-922.

ARRETCHE, M. T. S. O mito da descentralização como indutor de maior democratização e eficiência das políticas públicas. In: GERSCHMAN, S.; WERNECK VIANNA, M. L. T. (Org.). A miragem da pós-modernidade: Democracia e políticas sociais no contexto da globalização. Rio de Janeiro: Editora Fiocruz, 1997. p. 127-152.

BAÑON i MARTINEZ, R.; TAMAYO, M. Las relaciones intergubernamentales en España: el nuevo papel de la Administración Central en el modelo de relaciones intergubernamentales. In: AGRANOFF, R.; BAÑON i MARTINEZ, R. (Org.). El Estado de las Autonomías: hacia um nuevo federalismo? Bilbao: Instituto Vasco de Administración Pública, 1998. p. 105-159.

CARRILLO, E. El gobierno y la administración local en el Estado de las Autonomías. In: AGRANOFF, R.; BAÑON i MARTINEZ, R. (Org.). El Estado de las Autonomías: hacia um nuevo federalismo? Bilbao: Instituto Vasco de Administración Pública, 1998. p. 181-203.

DAWSON, B. Informe Dawson: Sobre el futuro de los servicios medicos y afines, 1920. Informe provisional presentado al Ministerio de Salud de la Gran Bretaña en 1920 por el consejo Consultivo de Servicios Médicos y Afines.Washington, DC: Organização Panamericana de la Salud, 1964. (Publicación cientifica nº 93).

ESPAÑA. Constituição Espanhola. Aprovada pelas Cortes em 31 de outubro de 1978. Ratificada pelo povo espanhol em 06 de dezembro de 1978. Sancionada pelo Rei em 27 de dezembro de 1978. Disponível em: <http://www.lamoncloa.gob.es/NR/rdonlyres/79FF2885-8DFA-4348-8450-04610A9267F0/0/ Constitucion_es.pdf >. Acesso em: 20 set. 2011.

Lei 14/1986 de 25 de abril. Disponível em: <https://www.boe.es/buscar/pdf/1986/BOE-A-198610499-consolidado.pdf>. Acesso em: 10 out. 2015.
Lei 16/2003 de 28 de maio. Disponível em: <http://www.boe.es/buscar/pdf/2003/BOE-A-200310715-consolidado.pdf >. Acesso em: 10 out. 2015.

FALLETI, T. G. Decentralization and subnational politics in Latin America. New York: Cambridge University Press, 2010.

FIORI, J. L. O federalismo diante do desafio da globalização. In.: AFFONSO, R. B. A.; SILVA, P. L. B. (Org.). A federação em perspectiva. São Paulo: FUNDAP, 1995. p. 19-38.

FLEURY, S.; OUVERNEY, A. M. Gestão de redes: a estratégia de regionalização da política de saúde. Rio de Janeiro: Editora FGV, 2007, 204 p.

FREIRE, J. M. La cobertura poblacional del Sistema Nacional de Salud: importancia y retos de la universalización y la equidad en el aseguramiento. In: REPULLO, J. R.; OTEO, L. A. (Org.). Un nuevo contrato social para un sistema nacional de salud sostenible. Barcelona: Editora Ariel, 2005. p. 61-99.

FREIRE, J. M. El Sistema Nacional de Salud español en perspectiva comparada europea: diferencias, similitudes, retos y opciones. Texto de trabajo. Madrid: 2008. 18 p.

GARCÍA, J. M.; SOTELO, J. A. España en los comienzos del siglo XXI: los contextos regionales. In: GARCÍA, J. M.; SOTELO, J. A. (Org.). La España de las Autonomías. Madrid: Editorial Síntesis, 1999. p. 14-28.

HALL, P.; TAYLOR, R. As três versões do neoinstitucionalismo. Lua Nova, São Paulo, n. 58, p. 193-224, 2003.

IMMERGUT, E. The theoretical core of the new institutionalism. Politics and Society, Los Angeles, v. 26, n. 1, p. 5-34, mar. 1998.

JORDANA, J. As comunidades autônomas e a política de descentralização na Espanha democrática. In: FLEURY, S. (Org.). Democracia, descentralização e desenvolvimento: Brasil e Espanha. Rio de Janeiro: Editora FGV, 2006. p. 213-238. 
KUSCHNIR, R.; CHORNY, A. H. Redes de atenção à saúde: contextualizando o debate. Ciência \&t Saúde Coletiva, Rio de Janeiro, v. 15, n. 5, p. 2307-2316, 2010.

LA MONCLOA. Gobierno de España. Disponível em: <http://www.lamoncloa.gob.es/home.htm>. Acesso em: 10 fev. 2012.

LIMA, L. D. et al. O pacto federativo brasileiro e o papel do gestor estadual do SUS. In.: UGÁ, M. A. et al. (Org.). Política de saúde no estado do Rio de Janeiro. Rio de Janeiro: Editora Fiocruz, 2010. p. 27-58.

MAINO, F. et al. Effects of decentralization and recentralization on political dimensions of health systems. In: SALTMAN, R. B.; BANKAUSKAITE, V.; VRANGBÆK, K. (Org.). Decentralization in health care: strategies and outcomes. England: Open University Press, 2007, p. 120-140.

MELO, M. A. Crise federativa, guerra fiscal e "hobbesianismo municipal”: efeitos perversos da descentralização? São Paulo em Perspectiva, São Paulo, v. 10, n. 3, 1996.

REQUEJO, F. Democracia, descentralização e pluralismo cultural: o caso do "Estado das autonomias" espanholas. In: FLEURY, S. (Org.). Democracia, descentralização e desenvolvimento: Brasil e Espanha. Rio de Janeiro: Editora FGV, 2006. p. 267-302.

ROCHA, C. V. Significados e tendências do federalismo e das relações intergovernamentais no Brasil e na Espanha. In.: HOCHMAN, G.; FARIA, C. A. P. Federalismo e políticas públicas no Brasil. Rio de Janeiro: Editora Fiocruz, 2013. p. 29-64.

SALTMAN, R. B.; BANKAUSKAITE, V.; VRANGBÆK, K. (Org.). Decentralization in health care: strategies and outcomes. England: Open University Press, 2007.
SISTEMA ESTADÍSTICO NACIONAL (INE). España. Disponível em: <http://www.ine.es/inebmenu/mnu_salud.htm>. Acesso em: 15 abr. 2013.

España em cifras. 2010. Disponível em: <http:// www.ine.es/prodyser/pubweb/espcif/espcif10.pdf>. Acesso em: 10 fev. 2012.

THELEN, K.; STEINMO, S. Historical institucionalism in comparative politics. In: THELEN, K.; STEINMO, S.; LONGSTRETH, F. (Org.). Structuring Politics. Historical Institucionalism in Comparative Analysis. Cambridge: Cambridge University Press, 1992.

VIANA, A. L. D. et al. Novas perspectivas para a regionalização da saúde. São Paulo em Perspectiva, São Paulo, v. 22, n. 1, p. 92-106, jan./jun. 2008.

VIANA, A. L. D.; LIMA, L. D. (Org.). Regionalização e relações federativas na política de saúde do Brasil. Rio de Janeiro: Contra Capa, 2011.

\section{WORLD HEALTH ORGANIZATION (WHO). Global}

Health Observatory Data Repository. Disponível em: <http://apps.who.int/ghodata/>. Acesso em: 10 fev. 2014.

YIN, R. K. Estudo de caso: planejamento e métodos. 3 ed. Porto Alegre: Bookman, 2005.

\footnotetext{
Recebido para publicação em maio de 2015

Versão final em outubro de 2015

Conflito de interesses: inexistente

Suporte financeiro: Coordenação de Aperfeiçoamento de Pessoal

de Nível Superior (Capes). Programa de Doutorado no País com estágio no exterior (PDSE). Processo BEX: 18719/12-0. E Conselho Nacional de Desenvolvimento Científico e Tecnológico (CNPq)
} 